\title{
Over Rate Emission Coefficient and Thunderstorm Algorithm for Dynamic Economic Dispatch
}

\author{
A.N. Afandi ${ }^{\# 1}$, A. Hermawan ${ }^{* 2}$, T. Winarno ${ }^{* 3}$ \\ \# Electrical Engineering Department, UniversitasNegeri Malang, Malang, JawaTimur, Indonesia \\ an.afandi@um.ac.id, an.afandi@ieee.org \\ *Electrical Engineering Department, PoliteknikNegeri Malang, Malang, JawaTimur, Indonesia \\ ${ }^{2}$ hermawanpolinema@gmail.com,3 totokwinarno@yahoo.com
}

\begin{abstract}
Since environmental requirements have penetrated the power system, its operation needs to consider the fossil burning together with reducing running charges of the fuel consumption.Technically, atmospheric emissions should be controlled economically at thermal power plants for $\mathbf{2 4}$ hours associated with a dynamic economic dispatch (DED). Thunderstorm algorithm (TA) is used to solve the DED problem considered an over rate emission coefficient applied to IEEE-62 bus system as a tested model. Moreover, this work also uses technical and environmental requirements of the operation. Simulation results show that TA can be used to obtain the optimal solution. The computational speed is performed in a smooth characteristic while searching the solution of the DED, which is carried out in hourly results.
\end{abstract}

Keyword-Dynamic Dispatch, Emission Coefficient, Power System, Thunderstorm Algorithm

\section{INTRODUCTION}

In general, power system operations are imposed in generation sections; transmission sections; distribution sections; and load sections, for conveying energy from generating sites to usage areas under a certain condition. Technically, these systems are operated using various strategies to exist generating units and to control power delivery processes. In addition, these processes are also operated to produce energy within a suitable power sharing for each power plant. In detail, the operation is conducted to technical and environmental constraints while distributing power outputs to load centres. Focused on these limitations, the environmental requirement is included in the operation especially at thermal power plants for reducing pollutants [1]-[4]. Moreover, pollutants are measured in an emission standard for decreasing and controlling various gaseous materials in air, such as $\mathrm{CO} ; \mathrm{CO}_{2} ; \mathrm{SO}_{\mathrm{x}}$; and $\mathrm{NO}_{\mathrm{x}}[4]-[9]$. In particular, technical limitations are also used to put desired power outputs in a scheduled permitted portion at generating units and power transfers at the lines in order to control and monitor the operation. In fact, the existed power system spends a certain budget for the energy production and infrastructure maintenance associated with generation sections; transmission sections; distribution sections. Financially, power plants take a role for this contribution spent in the fuel procurement at the all period time operation. Recently, it becomes one of the most important problems in the power system operation to reduce the technical cost through unit commitments. By considering this condition, the cost optimization is a significant case to obtain the best schedule and to meet the load demand under operational limitations belonged to equality and inequality constraints for the 24 hours operation [1]-[5], [8], [10]-[15].

To treat the whole operation for 24 hours, the power system operation becomes complex problems managed using economical cost strategies to provide electric energy and to match operational limitations. These strategies are used to select a better decision considered the minimum total operating cost as an economic load dispatch (ELD). Many studies have been reported concerned in the optimal operating cost based on the ELD[1], [7]-[8], [11]-[12], [14], [16]-[19]. Nowadays, the economic operation becomes more dynamic and interested issues to assess hourly performances related to demand changes under various themes; constraints; and requirements. In particular, it needs to plan economically based on complexity problems considered numerous limitations with the environmental penetration [5]-[7], [13], [20]-[23]. Practically, the load demand is growth from present hour to next hour during the operation. It will give an impact to power plants for producing energy at the whole operation. Regarding this behaviour, it becomes a crucial case to decide generation sites based on the balance of users and producers. By considering the power balance, the ELD is expanded to dynamic problems for 24 hours as a dynamic economic dispatch (DED) which is oriented to decrease the operating cost and pollutant production at the same time [20]-[23]. Many previous works have been focused on the DED solved using intelligent computation methods. These methods are frequently used to bring out the problems. It has shifted the classical method implementations, for instance, robust heuristic method; artificial immune system; neural network; particle swarm optimization; and harvest season artificial bee colony algorithm [20], [22]-[26]. 
Mathematically, the ELD is developed using a fuel consumption function to present generating unit processes while producing power outputs under technical constraints. This function is continued to adopt pollutant productions at thermal power units at the same duration as the impact of the environmental requirement to decline emissions in the air [7]-[9], [14]-[15]. In detail, this function uses a penalty factor to convert the emission production into a financial function and a weighting factor to take a portion of contributions on the ELD. Furthermore, this function is also modified to become a DED problem considered demand changes and hourly limits of productions. To carry out the objective function of the DED, in this paper, a new penalty factor approach is explored to cover the emission production and the fuel consumption. This paper also discusses thunderstorm algorithm (TA) as a new evolutionary algorithm to solve the DED problem.

\section{OVER RATE EMISSION COEFFICIENT}

In principles, the DED covers multiple operations considered hourly demand changes and sustainable power units online the system with available combinations for 24 hours. This problem is concerned in the power changes corresponded to ramp limits for allowing generation sites in permitted power changes while producing power outputs for the all period time operations under technical constraints [4], [20]-[22], [24], [27]. These limitations are also used to maintain mechanical effects in the rotor system during producing power outputs. By considering ramp limits, generating units are operated in allowed ranges of power changes to keep the life of the rotor [20], [22]. In this case, the DED cannot be solved as a single function and it is executed by considering several limitations, such as an equality power; power flows; losses; power limits; voltages; power transfers; ramp limits; and so on. Mathematically, in these works, the functions are studied as follows:

$\sum_{\mathrm{t}=1}^{\mathrm{T}} \mathrm{FC}_{\text {total }}^{\mathrm{t}}=\sum_{\mathrm{t}=1}^{\mathrm{T}} \sum_{\mathrm{i}=1}^{\mathrm{ng}}\left(\mathrm{c}_{\mathrm{i}}+\mathrm{b}_{\mathrm{i}} \cdot \mathrm{P}_{\mathrm{i}}^{\mathrm{t}}+\mathrm{a}_{\mathrm{i}}\left(\mathrm{P}_{\mathrm{i}}^{\mathrm{t}}\right)^{2}\right)$,

$\sum_{\mathrm{t}=1}^{\mathrm{T}} \mathrm{EM}_{\text {total }}^{\mathrm{t}}=\sum_{\mathrm{t}=1}^{\mathrm{T}} \sum_{\mathrm{i}=1}^{\mathrm{ng}}\left(\gamma_{\mathrm{i}}+\beta_{\mathrm{i}} \cdot \mathrm{P}_{\mathrm{i}}^{\mathrm{t}}+\alpha_{\mathrm{i}}\left(\mathrm{P}_{\mathrm{i}}^{\mathrm{t}}\right)^{2}\right)$,

$\sum_{\mathrm{t}=1}^{\mathrm{T}} \Phi_{\text {total }}^{\mathrm{t}}=\mathrm{w} \cdot\left(\sum_{\mathrm{t}=1}^{\mathrm{T}} \mathrm{FC}_{\text {total }}^{\mathrm{t}}\right)+(1-\mathrm{w}) \cdot\left(\sum_{\mathrm{t}=1}^{\mathrm{T}} \mathrm{h}^{\mathrm{t}} \cdot \mathrm{EM}_{\text {total }}^{\mathrm{t}}\right)$,

$\sum_{\mathrm{i}=1}^{\mathrm{ng}} \mathrm{P}_{\mathrm{i}}^{\mathrm{t}}=\mathrm{PD}_{\mathrm{i}}^{\mathrm{t}}+\mathrm{PL}_{\mathrm{i}}^{\mathrm{t}}$,

$P G_{p}^{t}=P D_{p}^{t}+V_{p}^{t} \cdot\left[\sum_{q=1}^{n B u s} V_{q}^{t}\left(G_{p q} \cdot \cos \left(\theta_{p q}^{t}\right)+B_{p q} \cdot \sin \left(\theta_{p q}^{t}\right)\right)\right]$,

$\mathrm{QG}_{\mathrm{p}}^{\mathrm{t}}=\mathrm{QD}_{\mathrm{p}}^{\mathrm{t}}+\mathrm{V}_{\mathrm{p}}^{\mathrm{t}} \cdot\left[\sum_{\mathrm{q}=1}^{\mathrm{nBus}} \mathrm{V}_{\mathrm{q}}^{\mathrm{t}}\left(\mathrm{G}_{\mathrm{pq}} \cdot \sin \left(\theta_{\mathrm{pq}}^{\mathrm{t}}\right)-\mathrm{B}_{\mathrm{pq}} \cdot \cos \left(\theta_{\mathrm{pq}}^{\mathrm{t}}\right)\right)\right]$,

$\mathrm{P}_{\mathrm{i}}^{\min } \leq \mathrm{P}_{\mathrm{i}}^{\mathrm{t}} \leq \mathrm{P}_{\mathrm{i}}^{\max }$,

$Q_{i}^{\min } \leq Q_{i}^{t} \leq Q_{i}^{\max }$,

$V_{\mathrm{p}}^{\min } \leq \mathrm{V}_{\mathrm{p}}^{\mathrm{t}} \leq \mathrm{V}_{\mathrm{p}}^{\max }$,

$\mathrm{S}_{\mathrm{pq}}^{\mathrm{t}} \leq \mathrm{S}_{\mathrm{pq}}^{\max }$,

$\mathrm{P}_{\mathrm{i}}^{\mathrm{t}}-\mathrm{P}_{\mathrm{i}}^{(\mathrm{t}-1)} \leq \mathrm{UR}_{\mathrm{i}}$,

$\mathrm{P}_{\mathrm{i}}^{(\mathrm{t}-1)}-\mathrm{P}_{\mathrm{i}}^{\mathrm{t}} \leq \mathrm{DR}_{\mathrm{i}}$.

Where $\mathrm{t}$ is period intervals of time $(\mathrm{t}=1,2,3, \ldots, \mathrm{T}), \mathrm{T}$ is a total time operation, $\mathrm{FC}_{\text {total }}^{\mathrm{t}}$ is total fuel cost of generating units $(\$ / \mathrm{hr})$ at the $\mathrm{t}^{\text {th }}$ of time, $\mathrm{P}_{\mathrm{i}}^{\mathrm{t}}$ is output power of $\mathrm{i}^{\text {th }}$ generating unit during time interval $\mathrm{t}(\mathrm{MW})$, ng is total number of generating units, $a_{i}, b_{i}, c_{i}$ are fuel cost coefficients of $i^{\text {th }}$ generating unit, $\mathbf{E M}_{\text {total }}^{t}$ is total emission of generating units $(\mathrm{kg} / \mathrm{hr})$ at the $\mathrm{t}^{\text {th }}$ of time, $\alpha_{\mathrm{i}}, \beta_{\mathrm{i}}, \gamma_{\mathrm{i}}$ are emission coefficients of $\mathrm{i}^{\text {th }}$ generating unit, $\Phi_{\text {total }}^{\mathrm{t}}$ is DED $(\$ / \mathrm{hr})$ at the $\mathrm{t}^{\text {th }}$ of time, the $\mathrm{h}^{\mathrm{t}}$ is a penalty factor at the $\mathrm{t}^{\text {th }}$ of time, $\mathrm{w}$ is a compromised factor, $\mathrm{PD}^{\mathrm{t}}$ is power load demand during interval $t, \mathrm{PL}^{\mathrm{t}}$ is transmission loss during time interval $t, \mathrm{PG}_{\mathrm{p}}{ }^{\mathrm{t}}$ andQG ${ }_{\mathrm{p}}{ }^{\mathrm{t}}$ are power injection of load flow at bus $\mathrm{p}$ during time interval $t, \mathrm{PD}_{\mathrm{p}}{ }^{\mathrm{t}}$ and $\mathrm{QD}_{\mathrm{p}}{ }^{\mathrm{t}}$ are load demand of load flow at bus $\mathrm{p}$ during time interval $t, \mathrm{~V}_{\mathrm{p}}{ }^{\mathrm{t}}$ and $\mathrm{V}_{\mathrm{q}}{ }^{\mathrm{t}}$ are voltage at bus $\mathrm{p}$ and $\mathrm{q}$ during time interval $\mathrm{t}, \mathrm{P}_{\mathrm{i}}{ }^{\text {min }}$ is minimum output power of the $i^{\text {th }}$ generating unit, $P_{i}{ }^{\text {max }}$ is maximum output power of the $i^{\text {th }}$ generating unit, $Q_{i}{ }^{\text {max }}$ and $Q_{i}{ }^{\text {min }}$ are maximum and minimum reactive power of $i^{\text {th }}$ generating unit, $Q_{i}{ }^{t}$ is reactive power output of $i^{\text {th }}$ generating unit during time interval $t$ (Mvar), $\mathrm{V}_{\mathrm{p}}{ }^{\max }$ and $\mathrm{V}_{\mathrm{p}}{ }^{\mathrm{min}}$ are maximum and minimum voltage at bus $\mathrm{p}, \mathrm{S}_{\mathrm{pq}}{ }^{\mathrm{t}}$ is power transfer between bus $p$ and $q$ during time interval $t$ (Mvar), $S_{p q}{ }^{\max }$ is limit of power transfer between bus $p$ and $q, U_{i}$ is up ramp limit of $\mathrm{i}^{\text {th }}$ generating unit and $\mathrm{DR}_{\mathrm{i}}$ is down ramp limit of $\mathrm{i}^{\text {th }}$ generating unit.

In addition, to present a dynamic problem, a penalty factor is one of the important variables for including the emission. This factor transfers the pollutant discharge into a financial compensation as an operating cost consequent for the emission at the thermal power plant. For a couple of years, a previous penalty factor approach has been used to define an environmental involvement in the total cost of fuel consumptions at generating units. This factor corresponds to maximum capacities of generating units online the power system while producing power outputs to serve the power demand and it refers to the ascending order technique [6], [14], [28]. In this section, a new penalty factor approach is explored as a dominant penalty factor (DPF) which is assumed that dominations of pollutant discharges come from larger emissions of generating units exceeded the allowed emission [4]. To show larger contributors, an over rate emission coefficient (OREC) is discussed in accordance to the produced emission. For each hourly process, it is performed using following expressions: 
$\operatorname{OREC}_{\mathrm{z}}^{\mathrm{t}}=\frac{\sum_{\mathrm{tu}=1}^{\mathrm{gu}} \mathrm{TPE}_{\mathrm{zs}}^{\mathrm{t}}-\sum_{\mathrm{tu}=1}^{\mathrm{gu}} \mathrm{TAE}_{\mathrm{zs}}^{\mathrm{t}}}{\mathrm{nG}_{\mathrm{z}}^{\mathrm{t}} \sum_{\mathrm{tu}=1}^{\mathrm{gu}} \mathrm{TPE}_{\mathrm{zs}}^{\mathrm{t}}}$

$\mathrm{h}_{\mathrm{z}}^{\mathrm{t}}=\left\{\mathrm{hG}_{\mathrm{zs}}^{\mathrm{t}}\right\}$,

$\mathrm{dh}_{\mathrm{z}}^{\mathrm{t}}=\mathrm{OREC}_{\mathrm{z}}^{\mathrm{t}} \cdot \mathrm{rh}_{\mathrm{z}}^{\mathrm{t}}$.

Where $\mathrm{OREC}_{z}^{t}$ is the over rate emission coefficient at the $\mathrm{t}^{\text {th }}$ hour of the $\mathrm{z}^{\text {th }}$ iteration; $\operatorname{TPE}_{\mathrm{zs}}^{\mathrm{t}}$ is the total produced emission at the $\mathrm{t}^{\text {th }}$ hour of the $\mathrm{s}^{\text {th }}$ generating unit of the $\mathrm{z}^{\text {th }}$ iteration $(\mathrm{kg} / \mathrm{h})$; $\mathrm{TAE}_{\mathrm{zs}}^{\mathrm{t}}$ is the total allowed emission at the $\mathrm{t}^{\text {th }}$ hour of the $\mathrm{s}^{\text {th }}$ generating unit of the $\mathrm{z}^{\text {th }}$ iteration $(\mathrm{kg} / \mathrm{h})$; gu is the number of generating units at the $\mathrm{t}^{\text {th }}$ hour of the $\mathrm{z}^{\text {th }}$ iteration; $\mathrm{nG}_{\mathrm{z}}^{\mathrm{t}}$ is the number of generating units at the $\mathrm{t}^{\text {th }}$ hour of the $\mathrm{z}^{\text {th }}$ iteration exceeded the allowed emission; $t$ is period intervals of time $(t=1,2,3, \ldots, T), T$ is a total time operation; $h_{z}^{t}$ is a penalty factor set at the $\mathrm{t}^{\text {th }}$ hour of the $\mathrm{z}^{\text {th }}$ iteration $(\$ / \mathrm{kg}) ; \mathrm{hG}_{\mathrm{zs}}^{\mathrm{t}}$ is the individual penalty factor at the $\mathrm{t}^{\text {th }}$ hour of the $\mathrm{s}^{\text {th }}$ generating unit exceeded the allowed emission of the $\mathrm{z}^{\text {th }}$ iteration step $(\$ / \mathrm{kg}) ; \mathrm{dh}_{\mathrm{z}}^{\mathrm{t}}$ is the dominant penalty factor at the $\mathrm{t}^{\text {th }}$ hour of the $\mathrm{z}^{\text {th }}$ iteration $(\$ / \mathrm{kg})$; and $\mathrm{rh}_{\mathrm{z}}^{\mathrm{t}}$ is the selected $\mathrm{hG}_{\mathrm{zs}}$ at the $\mathrm{t}^{\text {th }}$ hour of the $\mathrm{z}^{\text {th }}$ iteration for the highest $\mathrm{TPE}_{\mathrm{zs}}$.

\section{III.THUNDERSTORM ALGORITHM}

Many entities and mechanisms in nature have been adopted as an inspiration for presenting hierarchies and procedures while developing intelligent computations. Presently, natural behaviors and mechanisms become more attracting topics as previous works with numerous discussions for searching suitable models and understanding the natural phenomenon [1], [4]-[6], [9]-[10], [12], [14], [17]-[19]. In this section, thunderstorm mechanisms are adopted as an inspiration to construct TA presented in several stages and procedures. These mechanisms are mimicking the natural phenomena influenced by cloud conditions and potential factors for developing the striking line and streaming path [29]-[33]. The searching mechanism of TA for selecting solutions is conducted to striking processes and channelling avalanches for releasing the charge population. Moreover, TA also consists of various deployed distances associated with a hazardous factor (hf) for controlling positions of striking targets.

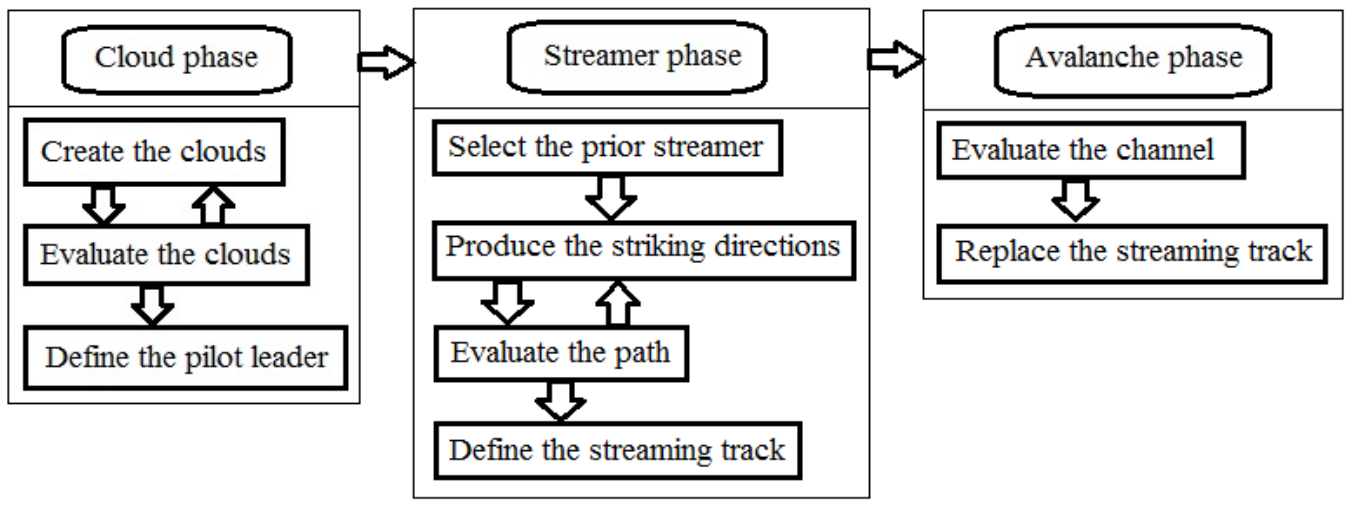

Fig. 1. Hierarchy processes of thunderstorm algorithm for each phase

In principle, the sequencing computation of TA is given in several mechanisms as pseudo-codes in terms of Cloud phase, Streamer phases, and Avalanche Phase [13], [34]. Cloud Phase covers for the creation of the clouds, evaluation of the clouds, and the defining pilot leader. Streamer Phase is used to select the prior streamer, generate striking directions, evaluate the striking path, and define the streaming track. Avalanche Phase is applied to evaluate the channels, replace the streamer, and keep the channel.

In detail, these mechanisms are illustrated in Fig. 1. Mathematically, TA is designed as follow:

Cloud charge: $Q_{s j}^{m}=(1+k . c) \cdot Q_{\text {midj }}^{m}$,

Striking path: $D_{\text {sj }}^{n}=\left(Q_{\text {sdep }}^{n}\right) \cdot b \cdot k$,

Probability charge: $\operatorname{prob}_{\mathrm{sj}}\left\{\begin{array}{l}\frac{\mathrm{Q}_{\mathrm{sj}}^{\mathrm{m}}}{\sum \mathrm{Q}_{\mathrm{s}}^{\mathrm{m}}} \text { for } \mathrm{m} \\ \frac{\mathrm{Q}_{\mathrm{sj}}^{\mathrm{n}}}{\sum \mathrm{Q}_{\mathrm{s}}^{\mathrm{n}}} \text { for } \mathrm{n}\end{array}\right.$, 
where $\mathrm{Q}_{\mathrm{sj}}$ is the current charge, $\mathrm{k}$ is the random number with [-1 and 1], $\mathrm{c}$ is the random within [1 and $\left.\mathrm{h}\right], \mathrm{Q}_{\text {midj }}$ is the middle charges, $s$ is the streaming flow, $j \in(1,2, . ., a)$, a is the number of variables, $m$ is the cloud size, $D_{s j}$ is the striking charge's position, $\mathrm{Q}_{\text {sdep }}$ is the deployed distance, $\mathrm{n}$ is the striking direction of the $\mathrm{h}^{\text {th }}$, $\mathrm{h}$ is the hazardous factor, $b$ is the random within (1-a).

\section{IV.Procedures AND TESTEd MODEL}

In these works, a standard model is adopted as a sample system conducted to the previous studies using IEEE's models. TheIEEE-62 bus system is selected for demonstrating TA to solve the DED problem considered various constraints. In detail, this system is structured using62 buses; 89 lines; and 32 load buses as illustrated in Fig. 2 as reported in [13], [34]. Furthermore, TA will be run in several programs covered the main program; evaluate the program; cloud charge program; streamer program; avalanche program; and dead track program. These programs will be integrated with its parameters in terms of 1 of the avalanche; 50 of the cloud charge; 100 of the streaming flows; and 4 of the hazardous factor. In addition, sequencing steps of TA are given in Fig. 3 with integrating phases to search the optimal solution. Respectively, coefficients and limits of generating units are given in Table I covered for the fuel consumption; emission; maximum and minimum powers including ramp limits. For the whole operation, hourly loads are modelled as listed in Table II.

TABLE I. Coefficients and Limits of Generators

\begin{tabular}{|c|c|c|c|c|c|c|c|c|c|c|c|c|}
\hline \multirow{2}{*}{ Gen } & \multicolumn{3}{|c|}{ FuelCoefficient } & \multicolumn{3}{|c|}{ Emission Coefficient } & \multicolumn{6}{|c|}{ Power limits } \\
\hline & $\mathbf{a}$ & b & c & $\alpha$ & $\beta$ & $\gamma$ & $\mathbf{P}_{\min }$ & $\mathbf{P}_{\max }$ & $\mathbf{Q}_{\min }$ & $\mathbf{Q}_{\max }$ & $\mathbf{D R}_{\mathbf{i}}$ & $\mathbf{U R}_{\mathbf{i}}$ \\
\hline G1 & 0.0070 & 6.80 & 95 & 0.018 & -1.81 & 24.30 & 50 & 300 & 0 & 450 & 65 & 102 \\
\hline $\mathrm{G} 2$ & 0.0055 & 4.00 & 30 & 0.033 & -2.50 & 27.02 & 50 & 450 & 0 & 500 & 65 & 153 \\
\hline G3 & 0.0055 & 4.00 & 45 & 0.033 & -2.50 & 27.02 & 50 & 450 & -50 & 500 & 65 & 153 \\
\hline G4 & 0.0025 & 0.85 & 10 & 0.014 & -1.30 & 22.07 & 0 & 100 & 0 & 150 & 25 & 34 \\
\hline G5 & 0.0060 & 4.60 & 20 & 0.018 & -1.81 & 24.30 & 50 & 300 & -50 & 300 & 65 & 102 \\
\hline G6 & 0.0055 & 4.00 & 90 & 0.033 & -2.50 & 27.02 & 50 & 450 & -50 & 500 & 65 & 153 \\
\hline G7 & 0.0065 & 4.70 & 42 & 0.013 & -1.36 & 23.04 & 50 & 200 & -50 & 250 & 65 & 68 \\
\hline G8 & 0.0075 & 5.00 & 46 & 0.036 & -3.00 & 29.03 & 50 & 500 & -100 & 600 & 65 & 170 \\
\hline G9 & 0.0085 & 6.00 & 55 & 0.040 & -3.20 & 27.05 & 0 & 600 & -100 & 550 & 75 & 204 \\
\hline G10 & 0.0020 & 0.50 & 58 & 0.014 & -1.30 & 22.07 & 0 & 100 & 0 & 150 & 25 & 34 \\
\hline G11 & 0.00450 & 1.60 & 65 & 0.014 & -1.25 & 23.01 & 50 & 150 & -50 & 200 & 65 & 51 \\
\hline G12 & 0.00250 & 0.85 & 78 & 0.012 & -1.27 & 21.09 & 0 & 50 & 0 & 75 & 25 & 17 \\
\hline G13 & 0.00500 & 1.80 & 75 & 0.018 & -1.81 & 24.30 & 50 & 300 & -50 & 300 & 65 & 102 \\
\hline G14 & 0.00450 & 1.60 & 85 & 0.014 & -1.20 & 23.06 & 0 & 150 & -50 & 200 & 75 & 51 \\
\hline G15 & 0.00650 & 4.70 & 80 & 0.036 & -3.00 & 29.00 & 0 & 500 & -50 & 550 & 75 & 170 \\
\hline G16 & 0.00450 & 1.40 & 90 & 0.014 & -1.25 & 23.01 & 50 & 150 & -50 & 200 & 65 & 51 \\
\hline G17 & 0.00250 & 0.85 & 10 & 0.014 & -1.30 & 22.07 & 0 & 100 & 0 & 150 & 25 & 34 \\
\hline G18 & 0.00450 & 1.60 & 25 & 0.018 & -1.81 & 24.30 & 50 & 300 & -50 & 400 & 65 & 102 \\
\hline G19 & 0.00800 & 5.50 & 90 & 0.040 & -3.00 & 27.01 & 100 & 600 & -100 & 600 & 130 & 204 \\
\hline & a: \$/MW & & & & $h^{2}, \beta: 1$ & $M U V h$ & ny & Q & ar $\mathrm{DR}$ & UR. & & \\
\hline
\end{tabular}




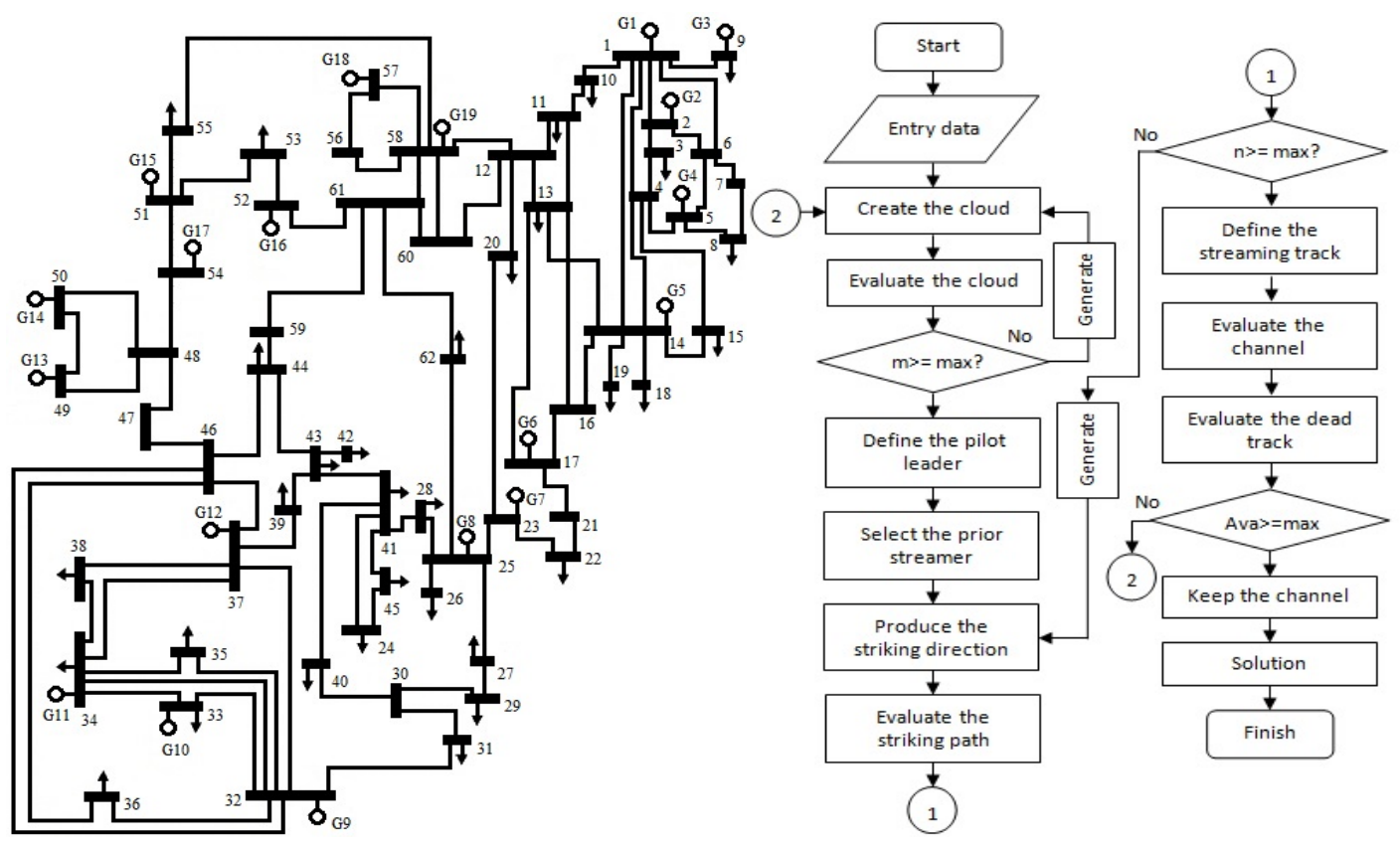

Fig. 2.IEEE 62-bus system

Fig. 3. Sequencing computations of TA

TABLE II.Hourly load demands

\begin{tabular}{|c|r|r|r|r|r|r|r|r|}
\hline \multicolumn{4}{|c|}{ Morning Load } & \multicolumn{3}{c|}{ Day Load } & \multicolumn{3}{c|}{ Night Load } \\
\hline Hour & \multicolumn{1}{|c|}{ MW } & \multicolumn{1}{|c|}{ MVar } & \multicolumn{1}{l|}{ Hour } & \multicolumn{1}{l|}{ MW } & \multicolumn{1}{l|}{ MVar } & Hour & MW & \multicolumn{1}{c|}{ MVar } \\
\hline 01.00 & $1,701.7$ & 741.3 & 09.00 & $2,456.0$ & $1,079.0$ & 17.00 & $2,446.2$ & $1,074.8$ \\
\hline 02.00 & $1,828.1$ & 796.8 & 10.00 & $2,716.9$ & $1,236.3$ & 18.00 & $2,722.0$ & $1,107.8$ \\
\hline 03.00 & $2,165.0$ & 943.5 & 11.00 & $2,892.0$ & $1,269.3$ & 19.00 & $2,871.6$ & $1,173.1$ \\
\hline 04.00 & $2,221.2$ & 968.1 & 12.00 & $2,746.7$ & $1,206.1$ & 20.00 & $2,751.6$ & $1,208.2$ \\
\hline 05.00 & $2,466.2$ & $1,074.8$ & 13.00 & $2,671.6$ & $1,173.1$ & 21.00 & $2,581.7$ & $1,133.8$ \\
\hline 06.00 & $2,221.2$ & 968.1 & 14.00 & $2,201.2$ & 968.1 & 22.00 & $2,243.3$ & 986.3 \\
\hline 07.00 & $2,316.0$ & $1,009.5$ & 15.00 & $2,371.1$ & $1,041.8$ & 23.00 & $1,906.4$ & 839.6 \\
\hline 08.00 & $2,371.1$ & $1,041.8$ & 16.00 & $2,406.2$ & $1,055.8$ & 24.00 & $1,505.5$ & 805.2 \\
\hline
\end{tabular}

By considering the DED's function and TA's parameters, the tested system is executed using $10 \%$ of the loss limit, 0.5 of the weighting factor, and $0.85 \mathrm{~kg} / \mathrm{hMW}$ of the emission standard. These studies are also conditioned by other constraints to search the suitable solution within $\pm 5 \%$ of voltage violations, $95 \%$ of the power transfer capability, and banded on upper and lower power outputs with the ramp allocations.

\section{RESUlts AND Discussions}

As mentioned before, these studies are used to solve the DED problem considered various loads and it is also used to evaluate the implementation of TA on the DED problem constrained by various limitations. In addition, these works are also used to demonstrate role of the OREC in the DED. In this section, TA is given in several performances for presenting its ability while solving the DED problem considered all constraints and parameters. All designed programs have been executed in an integrated sequencing order to obtain optimal solutions within 100 streaming flows for 24 hours. In detail, results are presented respectively in several indicators for illustrating the computation while searching the optimal solutions. 

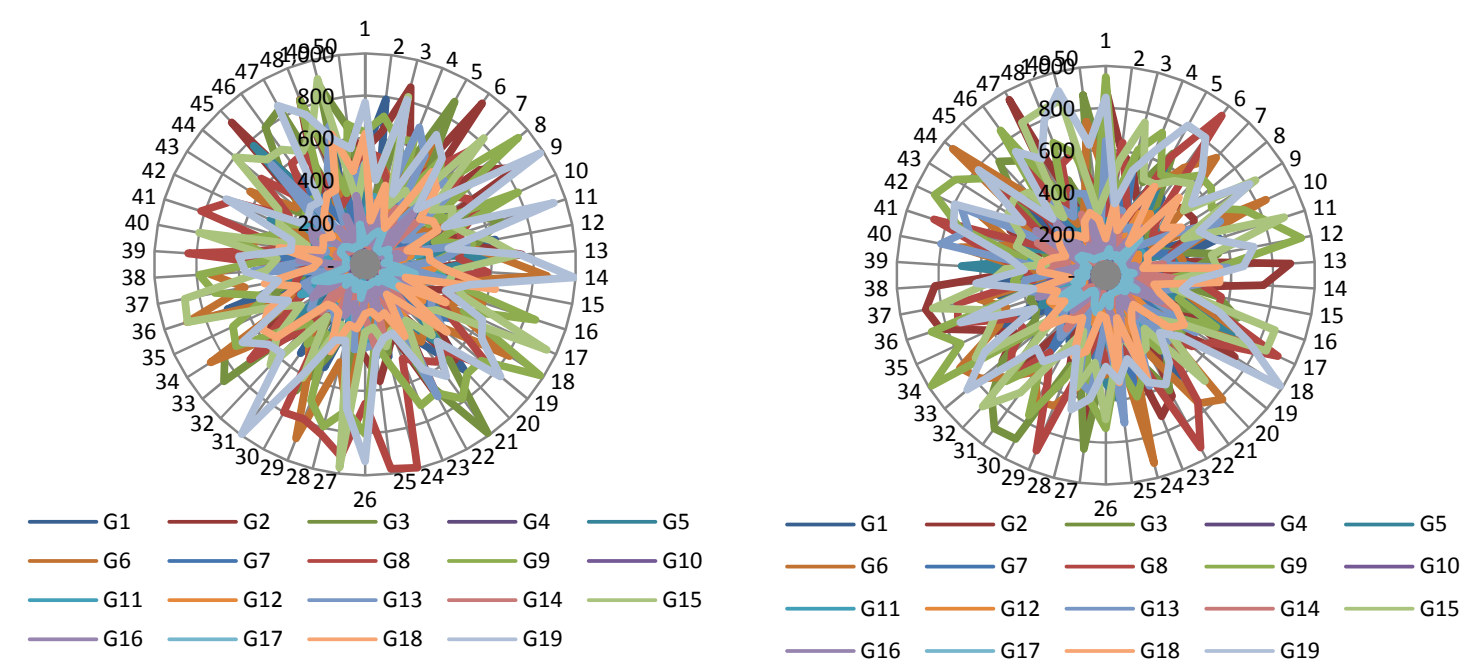

Fig. 4.The $1^{\text {st }}$ Cloud's charges $\quad$ Fig. 5. The $2^{\text {nd }}$ Cloud's charges
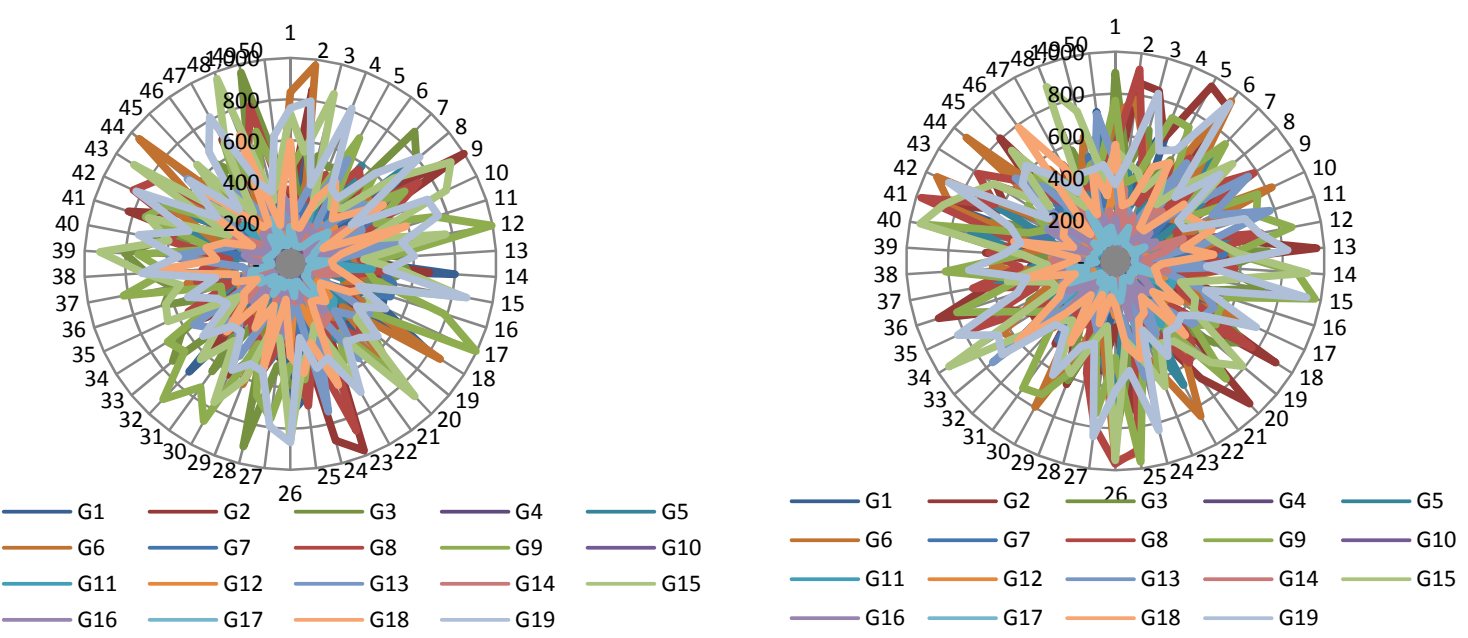

Fig. 6. The $3^{\text {rd }}$ Cloud's charges

Fig. 7. The $4^{\text {th }}$ Cloud's charges
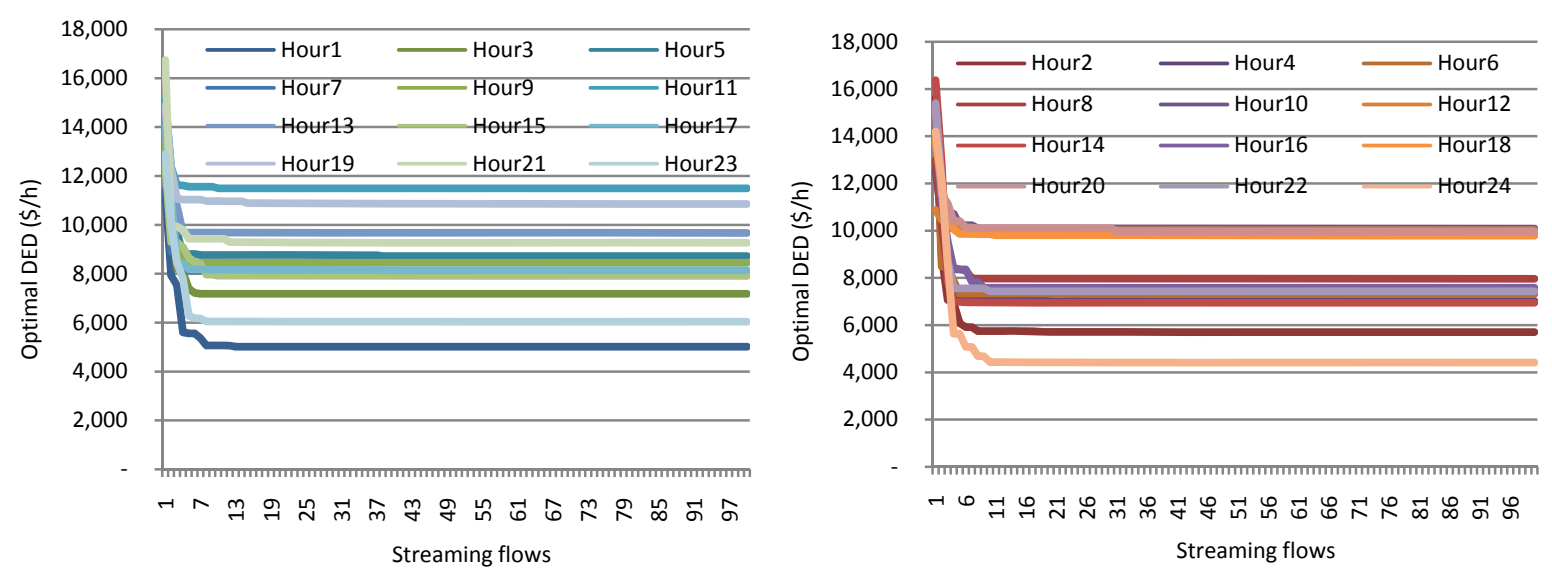

Fig. 8.Speeds of the odd computation

Fig. 9.Speeds of the even computation 


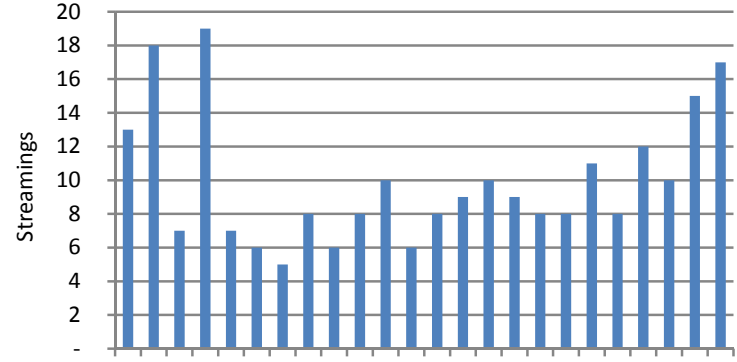

123456789101112131415161718192021222324

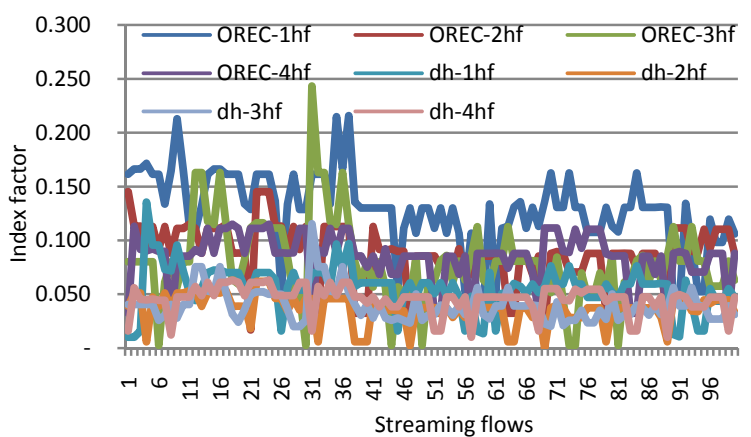

Fig.10. Obtained hourly optimal streaming

Fig. 11. Progressing dynamic factors and ORECs
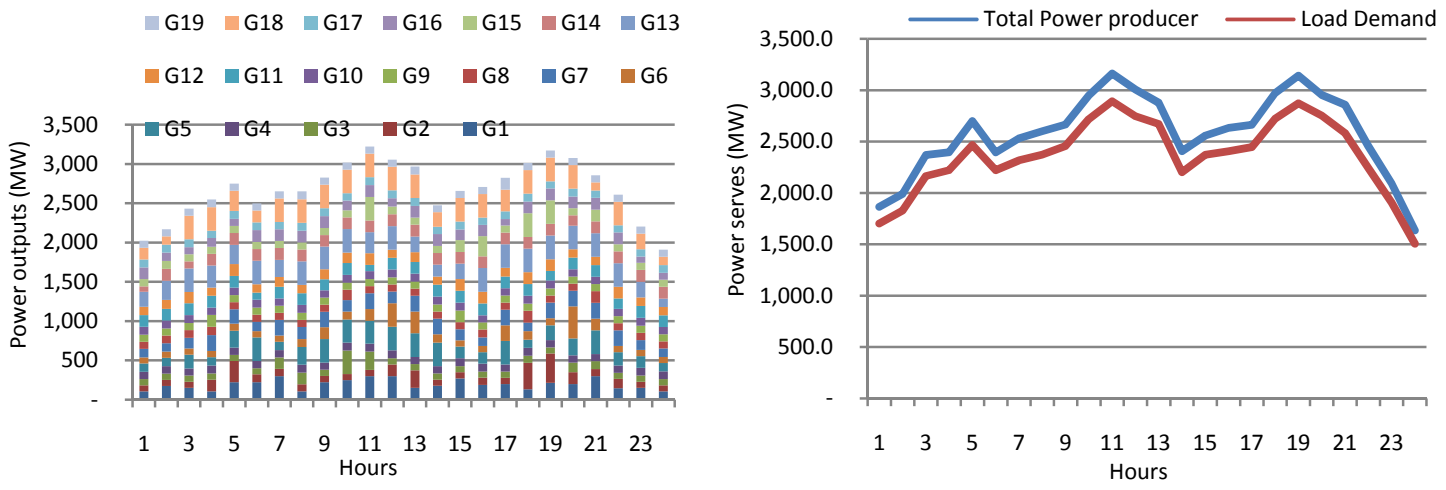

Fig. 12.Hourly power productions

Fig. 13.Hourly produced power balance
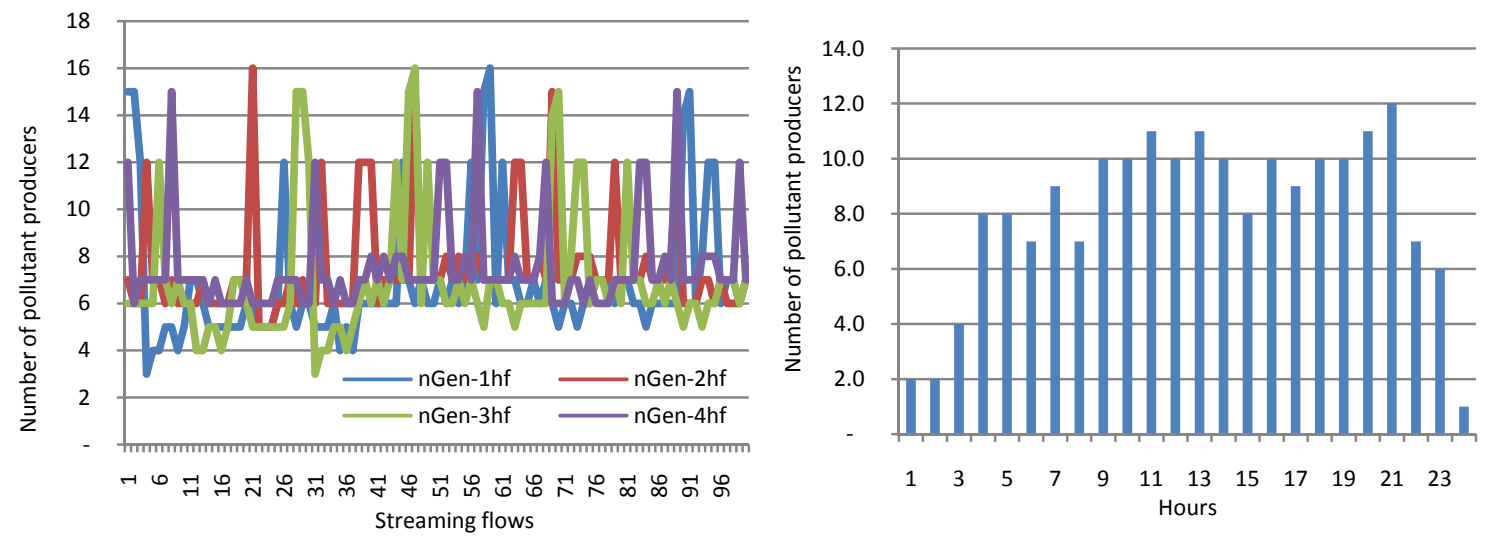

Fig. 14.Number of over emission contributors for each step

Fig. 15. Number of dominant pollutant producers for each hour

By considering 4 of the hazardous factor, TA has generated multiple striking directions at the streamer phase at all period time operations. Focused on solution candidates, four sets of the cloud are depicted in Fig. 4 to Fig. 7 for the possibility combination of 19 generating units as the population sets. These charges are provided in 50 pairs of suitable unit commitments for partial individual clouds. Moreover, Fig. 8 and Fig. 9 show characteristics of each computation while searching the optimal solution for each step. From these characteristics, it can be known that the processes are run in quick and smooth steps for 100 streaming flows. The optimal point for each step is provided in Fig. 10 for the solution shortly. This performance illustrates that hourly computation has an own obtained iteration for the optimal solution.

In particular, these works are addressed to find out unit commitments of 19 power stations for serving numerous demands as listed in Table II. By considering this hourly load, the power balance is given in Fig. 13. This performance is developed using 19 generating units throughout the optimal solution of the DED problem for covering loads and losses as listed in Table III. In detail, the own power production of the committed power producers is presented in Fig. 12. This result illustrates the combination for supporting the power system 
operation within 24 hours to meet each load demand. As the impact of these productions existed power plants also produce pollutants discharges in air.

TABLE III. Hourly operational results of optimal solutions

\begin{tabular}{|c|c|c|c|c|c|c|c|c|}
\hline \multirow{2}{*}{ Hour } & \multicolumn{2}{|c|}{ Power (MW) } & \multicolumn{2}{|c|}{ Loss } & \multicolumn{3}{|c|}{ Emission (kg) } & \multirow{2}{*}{$\begin{array}{l}\text { Operating } \\
\text { Cost (\$/h) }\end{array}$} \\
\hline & Load & Gen & MW & $\%$ & Product & Standard & Discharge & \\
\hline 01.00 & $1,701.7$ & $1,863.9$ & 162.2 & 8.7 & $1,947.5$ & $1,584.3$ & 174.5 & $8,013.7$ \\
\hline 02.00 & $1,828.1$ & $1,988.7$ & 160.6 & 8.1 & $2,233.5$ & $1,690.4$ & 83.0 & $8,330.5$ \\
\hline 03.00 & $2,165.0$ & $2,368.8$ & 203.8 & 8.6 & $5,767.4$ & $2,013.5$ & $1,423.1$ & $11,097.6$ \\
\hline 04.00 & $2,221.2$ & $2,393.9$ & 172.7 & 7.2 & $6,169.9$ & $2,034.8$ & $1,554.7$ & $11,359.7$ \\
\hline 05.00 & $2,466.2$ & $2,698.9$ & 232.7 & 8.6 & $9,429.8$ & $2,294.1$ & $2,967.7$ & $14,351.4$ \\
\hline 06.00 & $2,221.2$ & $2,392.1$ & 170.9 & 7.1 & $5,552.4$ & $2,033.3$ & $1,483.4$ & $11,886.8$ \\
\hline 07.00 & $2,316.0$ & $2,530.6$ & 214.6 & 8.5 & $5,998.9$ & $2,151.0$ & $1,656.8$ & $12,631.1$ \\
\hline 08.00 & $2,371.1$ & $2,598.5$ & 227.4 & 8.8 & $8,033.4$ & $2,208.7$ & $2,192.9$ & $12,644.8$ \\
\hline 09.00 & $2,456.0$ & $2,664.0$ & 208.0 & 7.8 & $7,772.4$ & $2,264.4$ & $2,175.7$ & $13,468.1$ \\
\hline 10.00 & $2,716.9$ & $2,947.4$ & 230.5 & 7.8 & $13,198.9$ & $2,505.3$ & $4,702.0$ & $17,189.8$ \\
\hline 11.00 & $2,892.0$ & $3,160.7$ & 268.7 & 8.5 & $15,094.8$ & $2,686.6$ & $5,724.1$ & $19,598.5$ \\
\hline 12.00 & $2,746.7$ & $3,004.9$ & 258.2 & 8.6 & $13,949.8$ & $2,554.2$ & $5,331.7$ & $18,445.1$ \\
\hline 13.00 & $2,671.6$ & $2,877.2$ & 205.6 & 7.1 & $12,186.2$ & $2,445.6$ & $4,043.8$ & $15,897.5$ \\
\hline 14.00 & $2,201.2$ & $2,405.1$ & 203.9 & 8.5 & $5,046.4$ & $2,044.3$ & 935.8 & $11,302.7$ \\
\hline 15.00 & $2,371.1$ & $2,556.3$ & 185.2 & 7.2 & $6,844.3$ & $2,172.9$ & $1,884.4$ & $12,757.0$ \\
\hline 16.00 & $2,406.2$ & $2,631.3$ & 225.1 & 8.6 & $9,457.9$ & $2,236.6$ & $2,926.9$ & $13,529.1$ \\
\hline 17.00 & $2,446.2$ & $2,663.2$ & 217.0 & 8.1 & $8,814.8$ & $2,263.7$ & $2,681.9$ & $14,161.3$ \\
\hline 18.00 & $2,722.0$ & $2,971.1$ & 249.1 & 8.4 & $16,910.6$ & $2,525.4$ & $6,318.2$ & $18,049.6$ \\
\hline 19.00 & $2,871.6$ & $3,140.0$ & 268.4 & 8.5 & $19,372.6$ & $2,669.0$ & $7,548.4$ & $20,610.6$ \\
\hline 20.00 & $2,751.6$ & $2,951.5$ & 199.9 & 6.8 & $13,314.0$ & $2,508.8$ & $4,644.9$ & $16,985.7$ \\
\hline 21.00 & $2,581.7$ & $2,856.7$ & 275.0 & 9.6 & $10,186.7$ & $2,428.2$ & $3,533.1$ & $16,632.4$ \\
\hline 22.00 & $2,243.3$ & $2,455.1$ & 211.8 & 8.6 & $5,650.7$ & $2,086.8$ & $1,041.1$ & $11,057.6$ \\
\hline 23.00 & $1,906.4$ & $2,092.9$ & 186.5 & 8.9 & $2,791.7$ & $1,779.0$ & 168.3 & $8,921.8$ \\
\hline 24.00 & $1,505.5$ & $1,634.9$ & 129.4 & 7.9 & 944.7 & $1,389.7$ & 4.5 & $7,031.1$ \\
\hline Total & $56,780.5$ & $61,847.7$ & 5,06 & & $206,669.3$ & $52,570.6$ & $65,200.9$ & $325,953.5$ \\
\hline
\end{tabular}

By considering pollutant discharges, Fig. 14 shows produced pollutants exceeded the standard for each step. According to Fig. 14, the contributor of the OREC comes from different portions in the power unit commitment. For this process, the involvement in the DED is presented in Fig. 15 depicted for 24 hours related to the hazardous factor. In detail, its production is listed in Table III for the emission within 24 hours included powers and operating costs. From this table, it is known that a day operation produces totally the power output around 61,847.7 MW to serve 56,780.5 MW of the total load. This power is also absorbed by the lines while transmitting energy to users around $5,067.2 \mathrm{MW}$, even it is still under $10 \%$ as required for the loss. For 24 hours, this operation spent the load in $325,953.5 \$$ for the fuel consumption and the emission compensation of $65,200.9 \mathrm{~kg}$. In addition, power plants discharge the total emission in $206,669.3 \mathrm{~kg}$ which is limited by $52,570.6$ $\mathrm{kg}$.

\section{VI.CONCLUSIONS}

This paper presents an application of Over Rate Emission Coefficient (OREC) and Thunderstorm Algorithm (TA) to the optimal solution of the dynamic economic dispatch (DED) problem using IEEE-62 bus system as the tested model. The DED is constrained by operational limitations and an emission standard for 24 hours. Obtained results show that power outputs are produced hourly in various portions as same as emission discharges or financial usages. Based on the results, TA obtained the optimal solution in different speeds and iterations for the DED. The OREC and emissions product have been also contributed in different number of participants for each hour and step. From these works, an application on a real large system is devoted to the future studies. 


\section{REFERENCES}

[1] Ioannis G. Damausis, Anastasios G. Bakirtzis, Petros S. Dokopoulos, "Network constrained economic dispatch using real coded genetic algorithm," IEEE Trans. Power Systems, vol.18, no. 1, pp. 198-205, Feb. 2003.

[2] Yong Fu, Mohammad Shahidehpour, Zuyi Li, "AC Contingency dispatch based on security constrained unit commitment," IEEE Transactions on Power Systems, vol. 21, no. 2, pp. 897-908, May. 2006.

[3] ZeljkoBogdan, MislavCehil, DamirKopjar, "Power system optimization," Energy, vol. 3, pp. 955-960, Apr. 2007.

[4] A.N. Afandi, "Optimal scheduling power generations using HSABC Algorithm Considered a New Penalty Factor Approach," in Proc. IEEE Conference on Power Engineering and Renewable Energy, 16-18 December 2014, Bali, p. 17-18.

[5] Yunzhi Cheng, Weiping Xiao, Wei-Jen Lee and Ming Yang, "A new approach for emissions and security constrained economic dispatch," in Proc. NAPS IEEE Conference, 4-6Oct. 2009, Starkville, p. 1-5.

[6] R. Gopalakrishnan, A. Krishnan, "A novel combined economic and emission dispatch problem solving technique using non-dominated ranked genetic algorithm," European Journal of Scientific Research, vol. 64, no. 1, pp. 141-151, Nov. 2011.

[7] MukeshGarg, Surender Kumar, "A survey on environmental economic load dispatch using lagrange multiplier method," International Journal of Electronics \& Communication Technology, vol. 3, no. 1, pp. 43-46, Jun. 2012.

[8] B.H. Chowdhury, SaifurRahman, "A review of recent advances in economic dispatch," IEEE Trans. On Power Systems, vol. 5, no. 4,pp. 1248-1259, Nov. 1990.

[9] A.A. El-Keib, H.Ma, and J.L. Hart, "Environmentally constrained ED using the Lagrangian relaxation method," IEEE transactions on Power Systems, vol. 9, no. 4, pp. 533-534, Nov. 1994.

[10] S. Subramanian, and S. Ganesa, "A simplified approach for ED with piecewise quadratic cost functions," InternationalJournal of Computer and Electrical Engineering, vol. 2, no. 5, pp. 793-798, Oct. 2010.

[11] A.N. Afandi, Hajime Miyauchi, "Improved artificial bee colony algorithm considering harvest season for computing economic dispatch on power system," IEEJ Transactions on Electrical and Electronic Engineering, vol. 9, no. 3, pp. 251-257, May 2014.

[12] H. ChahkandiNejad, R. Jahani, M. Mohammad Abadi, "GAPSO-based economic load dispatch of power system," Australian Journal of Basic and Applied Sciences, vol. 5, no. 7, pp. 606-611, Jul. 2011.

[13] A.N. Afandi, "Thunderstorm algorithm for assessing thermal power plants of the integrated power system operation with an environmental requirement," International Journal of Engineering and Technology, vol. 8, no. 2, pp. 1102-1111, May 2016.

[14] K. Sathish Kumar, V.Tamilselvan, N.Murali, R.Rajaram, N.ShanmugaSundaram and T.Jayabarathi, "Economic load dispatch with emission constraints using various PSO algorithm,” WSEASTransaction on Power System, vol. 9, no. 3, pp. 598-607, Sept. 2008.

[15] A.N. Afandi, Hajime Miyauchi, "Solving combined economic and emission dispatch using harvest season artificial bee colony algorithm considering food source placements and modified rates, 'International Journal on Electrical Engineering and Informatics, vol. 6, no. 2, pp. 266-279, Jun. 2014.

[16] Ahmed Farag, Samir Al-Baiyat, T.C. Cheng, "Economic load dispatch multiobjective optimization procedures using linear programming techniques,” IEEE Trans. Power Systems. Vol. 10, no. 2, pp. 731-738, May 1995.

[17] M. A. Aziz, J. I. Musirinand T. K. A. Rahman, "Solving dynamic ED using evolutionary programming," in Proc. First International Power and Energy Conference, 8-12 Jul.2006, Canada, p. 144-149.

[18] T. Yalcinoz and M. J. Short, "Large-scale ED using an improved hopfield neural network," IEE Proc. Gener. Transm. Distrib., vol. 144, no. 2, pp. 181-185, Mar. 1997.

[19] A.N. Afandi, "Optimal solution of the EPED problem considering space areas of HSABC on the power system operation," International Journal of Engineering and Technology, vol. 7, no. 5, pp. 1824-1830, Nov. 2015.

[20] Hemamalini, Sishaj P. Simon, "Dynamic economic dispatch using artificial bee colony algorithm for units with valve-point effect," Euro. Trans. Electr. Power, vol. 21, no. 1, pp. 70-81, Jan. 2011.

[21] DevendraBisen, Hari Mohan Dubey, "Dynamic economic load dispatch with emission and loss using GAMS," International Journal of Engineering Research \& Technology, vol. 1, no. 3, pp. 1-7, May. 2012.

[22] X.S. Han, H.B. Gooi, D.S. Kirschen, "Dynamic economic dispatch: Feasible and optimal solutions," IEEE Trans. Power Syst., vol. 16 , no. 1, pp. 22-28., Feb. 2001.

[23] R.H. Liang, "A neural based redispatchapproach to dynamic generation allocation," IEEE Trans. Power Systems, vol. 14, no. 4,pp. 1388-1393, Nov. 1999.

[24] A.N. Afandi, Fadlika I., Sulistyorini Y., "Solution of dynamic economic dispatch considered dynamic penalty factor," in Proc. The 3rd IEEE Conference on Power Engineering and Renewable Energy, 29-30 Nov.2016, Yogyakarta, p. 241 - 246.

[25] Z.L. Gaing, et al., "Constrained dynamic economic dispatch solution using particle swarm optimization," IEEE Power Eng. Soc. Gen. Meet, vol. 1, no. 1, pp. 153-158, Jun. 2004.

[26] EfrenMezura Montes, Mauricio Damian Araoz, Omar CentinaDominges, "Smart flight and dynamic tolerances in the artificial bee colony for constrained optimization," in Proc. IEEE Congress on Evolutionary Computation CEC, 18-24 Jul. 2010, Barcelona p. 1-8.

[27] H. Shayeghi, A. Ghasemi, "Application of MOFSO for economic load dispatch solution with transmission losses," International Journal on Technical and Physical Problems of Engineering, vol. 4, no. 1, pp. 27-34, Mar. 2012.

[28] A.N. Afandi, YunisSulistyorini, "Thunderstorm algorithm for determining unit commitment in power system operation," Journal of Engineering and Technological Sciences, vol. 48, no. 6, pp. 743-752, Dec. 2016.

[29] T. J. Lang, S. A. Rutledge, and K. C. Wiens, "Origins of positive cloud-to-ground lightning flashes in the stratiform region of a mesoscale convective system," Geophys. Res. Lett, vol. 31, pp. 1-4, Apr. 2004.

[30] L. D. Carey, S. A. Rutledge, and W. A. Petersen, "The Relationship B-between severe storm reports and cloud-to-ground lightning polarity in the contiguous united states from 1989 to 1998," Mon. Wea. Rev., pp. 1211-1228, Jul. 2003.

[31] D.R. Macgorman, W.D. Rust, P. Krehbiel, W. Rison, E. Bruning, and K. Wiens, "The electrical structure of two supercell storms during STEPS,” Mon. Wea. Rev., pp. 2583-2607, Sep. 2005.

[32] E. R. Mansell, D. R. Macgorman, C. L. Zeigler, and J. M. Straka, "Charge structure and lightning sensitivity in a simulated multicell thunderstorm," J. Geophys. Res, vol. 110, no. D12, pp. 110, Jun. 2005.

[33] M. Stolzenburg and T. C. Marshall, "Charge structure and dynamics in thunderstorms," Space Sci. Rev., pp. 1-4, 2008.

[34] A.N. Afandi, Irham Fadlika, Andoko, "Comparing performances of evolutionary algorithms on the emission dispatch and economic dispatch problem,” Telkomnika Journal, vol. 13, no. 4, pp. 1187-1193, Dec. 2015. 